\title{
Determination of genetic aberrations and novel transcripts involved in the pathogenesis of oligodendroglioma using array comparative genomic hybridization and next generation sequencing
}

\author{
SITI A. HASSANUDIN, STEPHEN N. PONNAMPALAM and MUHAMMAD N. AMINI \\ Cancer Research Center, Institute for Medical Research, Jalan Pahang, 50588 Kuala Lumpur, Malaysia
}

Received February 22, 2018; Accepted September 17, 2018

DOI: $10.3892 / \mathrm{ol} .2018 .9811$

\begin{abstract}
The aim of the present study was to determine the genetic aberrations and novel transcripts, particularly the fusion transcripts, involved in the pathogenesis of low-grade and anaplastic oligodendroglioma. In the present study, tissue samples were obtained from patients with oligodendroglioma and additionally from archived tissue samples from the Brain Tumor Tissue Bank of the Brain Tumor Foundation of Canada. Six samples were obtained, three of which were low-grade oligodendroglioma and the other three anaplastic oligodendroglioma. DNA and RNA were extracted from each tissue sample. The resulting genomic DNA was then hybridized using the Agilent CytoSure 4x180K oligonucleotide array. Human reference DNA and samples were labeled using Cy3 cytidine 5'-triphosphate (CTP) and Cy5 CTP, respectively, while human Cot-1 DNA was used to reduce non-specific binding. Microarray-based comparative genomic hybridization data was then analyzed for genetic aberrations using the Agilent Cytosure Interpret software v3.4.2. The total RNA isolated from each sample was mixed with oligo dT magnetic beads to enrich for poly(A) mRNA. cDNAs were then synthesized and subjected to end-repair, poly(A) addition and connected using sequencing adapters using the Illumina TruSeq RNA Sample Preparation kit. The fragments were then purified and selected as templates for polymerase chain reaction amplification. The final library was constructed with fragments between 350-450 base pairs and sequenced using deep transcriptome sequencing on an Illumina HiSeq 2500 sequencer. The array comparative genomic hybridization revealed numerous amplifications and deletions on several chromosomes in all samples. However, the most interesting result was from the next generation sequencing,
\end{abstract}

Correspondence to: Dr Stephen N. Ponnampalam, Cancer Research Center, Institute for Medical Research, Jalan Pahang, 50588 Kuala Lumpur, Malaysia

E-mail: ponnams99@yahoo.com

Key words: oligodendroglioma, genetic aberrations, novel transcripts, fusion genes, next generation sequencing where one anaplastic oligodendroglioma sample was demonstrated to have five novel fusion genes that may potentially serve a critical role in tumor pathogenesis and progression.

\section{Introduction}

Cancer is the leading cause of morbidity and mortality globally (1). Brain and other central nervous system tumor types are common amongst adults and children, ranking 17th in incidence among all cancer types globally (2) and is the 2 nd leading cause of mortality in the pediatric age group (3).

Brain tumor types are either primary or secondary (4). Currently, there exists a World Health Organization (WHO) classification for the prognostication of gliomas based on their morphological characteristics. Oligodendrogliomas are divided into low-grade (WHO Grade II) and anaplastic (WHO Grade III) tumor types. Astrocytic tumor types are classified into low-grade diffuse astrocytoma (WHO Grade II), anaplastic astrocytoma (WHO Grade III) and glioblastoma multiforme (GBM) and its variants (WHO Grade IV) (4). GBM is the most malignant and aggressive of these tumor types (4).

Conventionally, brain tumor types are diagnosed by imaging. In certain cases, imaging may not be adequate to reach a diagnosis, so a biopsy and histopathological examination of the tissue may be required (5). The molecular genetics of tumor cells serve a notable role in the pathogenesis of brain tumor types. This is particularly the case for oligodendrogliomas that have their own unique set of alterations, with the most notable being the loss of heterozygosity ( $\mathrm{LOH})$ on chromosomal arms 1p/19q. LOH 1p/19q has emerged as an independent predictive marker of an improved response to radio- and chemotherapy in addition to prolonged overall survival in anaplastic oligodendrglioma (6-11). Combined with the status of isocitrate dehydrogenase 1 and 2 and tumor protein p53 (TP53) mutations, the prognosis and diagnosis of distinct subgroups of gliomas has become dependent on these genetic alterations due to their functions in these tumor types $(12,13)$.

Over the years, fluorescence in situ hybridization (FISH) analysis has become a useful diagnostic test to determine the molecular profile of oligodendrogliomas, along with other techniques including microsatellite markers and array 
comparative genomic hybridization (aCGH) (14). There are several disadvantages to using FISH, one of which is the decreasing intensity of the signals over time. Other limitations include the need to optimize the control probes for each locus, which may be time-consuming and costly (14).

Using aCGH as a clinical tool has proven to be more useful and reliable compared with FISH as it is able to detect a wide and extensive number of genetic changes in one screening of the human genome. It is a highly sensitive tool that is able to distinguish even the smallest genomic regions and subtlest DNA copy number difference (15). A study by Mohapatra et al (15), demonstrated this by using formalin-fixed, paraffin-embedded oligodendroglioma samples in aCGH analysis with a novel labelling technique to generate high-quality hybridization probes. It was hypothesized that aCGH was able to detect single copy losses and 50\% more DNA losses in the cells when compared with FISH analysis (15).

In more recent years, a method to analyze the entire genome has been identified through the use of next generation sequencing (NGS) technologies $(16,17)$. There are a number of techniques that fall under the definition of NGS including whole genome, whole exome and RNA sequencing. NGS is a method that is able to provide in-depth information regarding the functionalities of the whole genome including its genomic alterations, transcriptional changes, gene fusions and alternative splicing (16,17). RNA sequencing (RNA-Seq) in particular, is a high-throughput whole transcriptome sequencing technology that utilizes isolated RNA for deep sequencing for profiling and generates comprehensive transcriptomic information of the cells. Previous studies have been performed using NGS to provide an RNA-Seq profiling dataset and identify biomarkers for diagnosis and prognosis with the potential to be candidate genes for glioma therapy (18-20). The main objective of the present study was to capture the transcriptomic landscape along the pathogenesis of oligodendrogliomas from low-grade to high-grade tumor progression. Using aCGH and NGS, the present study also aimed to identify differentially expressed genes, genetic aberrations and novel markers involved in the pathogenesis of oligodendrogliomas.

\section{Materials and methods}

Clinical patient data. Patient samples of 6 patients were collected from the respective hospitals for a period of 3 years between 1st January 2014 and 31st December 2016. A select number of archived samples were also obtained from the Brain Tumor Tissue Bank (Brain Tumor Foundation of Canada, London, ON, Canada) due to the limited availability of samples obtained from patients. Upon admission to the hospital, demographic data and a brief clinical history were elicited from the patients. This included the age and sex of the patient and the state in which the patient was domiciled. The final selection of 6 patients consisted of 3 low-grade oligodendroglioma and 3 anaplastic oligodendroglioma cases (Table I). Written informed consent was obtained prior to brain tumor removal from the patient during surgery. Subsequent to obtaining consent, surgery was performed the next day, typically within 12-24 h. In addition, the present study received ethical approval from the Medical Research Ethics Committee of the Ministry of Health (Putrajaya, Malaysia).
Tissue sample collection. The tumor samples were collected and then inserted into a PAXgene ${ }^{\mathrm{TM}}$ Tissue Container (Qiagen $\mathrm{GmbH}$, Hilden, Germany). The tissue specimens were placed first into a standard tissue cassette. The cap of the PAXgene Tissue Container was then unscrewed and lifted up to remove the screw cap-rack assembly. The tissue cassette was attached to the rack by inserting the lower edge of the tissue cassette into the bottom edge of the rack and pressed to secure it under the rack upper release tab. Then, the rack holding the tissue cassette was placed into chamber 1 containing the PAXgene Tissue Fix solution and capped into place. Fixation of the tissue was performed at room temperature for 2-4 h. Following fixation, the cap was unscrewed and lifted up to remove the screw cap-rack assembly with the tissue cassette from chamber 1 . The rack-tissue cassette was then placed directly above chamber 2 which contained the PAXgene Tissue Stabilizer and submerged with the cap screw tightened. The PAXgene Tissue Container was then stored at $-80^{\circ} \mathrm{C}$ until required for further experimentation.

DNA and RNA extraction. Approximately $20 \mathrm{mg}$ tissue specimens were harvested by placing them in $350 \mu \mathrm{l}$ buffer cytotoxic T-lymphocyte with $\beta$-mercaptoethanol (GeneAll Biotechnology Co., Ltd., Seoul, South Korea) followed by complete homogenizing with a handheld rotor-stator TissueRuptor (Qiagen GmbH, Hilden, Germany) for $30 \mathrm{sec}$. The lysates were left to incubate for $10 \mathrm{~min}$ at room temperature, allowing the nucleoprotein complexes to completely dissociate. The lysates were then centrifuged at $10,000 \mathrm{x} g$ for 3 min and the supernatant transferred to a mini spin column. The mini spin column containing the supernatant was then centrifuged at $\geq 10,000 \mathrm{x}$ g for $30 \mathrm{sec}$ at room temperature. The pass-through was used for total RNA purification while the spin column with the DNA bound to the membrane was transferred to a new collection tube and used for DNA purification. The pass-through in the previous collection tube (for total RNA purification) was mixed with an equal volume of $70 \%$ ethanol prior to being transferred to another new mini spin column (type W, blue ring). A series of centrifugation steps for total RNA purification were performed (Allspin ${ }^{\mathrm{TM}}$ Total DNA/RNA Purification kit; GeneAll Biotechnology Co., Ltd., Seoul, Korea) according to the manufacturer's protocol. The purified RNA bound to the membrane was then eluted with $50 \mu$ l nuclease-free water. The mini column containing the membrane bound DNA also underwent a series of centrifugation steps for total DNA purification and was eluted in $100 \mu \mathrm{l}$ nuclease-free water. DNA was stored at $-20^{\circ} \mathrm{C}$ until further use.

DNA analysis. Concentration and purity of the DNA was analyzed using the Spectrophotometer NanoDrop ND-1000 (Thermo Fisher Scientific, Inc., Waltham, MA, USA). The integrity of the genomic DNA was analyzed using the Agilent Genomic DNA ScreenTape System (Agilent Technologies, Inc., Santa Clara, CA, USA). The DNA concentration ranged from 205.6 to $582.6 \mathrm{ng} / \mu 1$ while the mean DNA integrity number was 8.28 with a standard deviation of 1.06 .

RNA analysis. Concentration and purity of the RNA was analyzed similar to that for DNA. The integrity of the RNA was analyzed using the Agilent 2100 BioAnalyzer RNA 6000 Nano 
Table I. Patient demographics and histopathology of tumor types.

\begin{tabular}{lccllc}
\hline Patient & Sample no. & Age (years) & Sex & \multicolumn{1}{c}{ Histopathology } & Grade \\
\hline 1 & 88 & 23 & Male & Low grade oligodendroglioma & II \\
2 & 1578 & 34 & Female & Low grade oligodendroglioma & II \\
3 & 1090 & 37 & Female & Low grade oligodendroglioma & II \\
4 & 1385 & 35 & Female & Anaplastic oligodendroglioma & III \\
5 & 1395 & 44 & Female & Anaplastic oligodendrglioma & III \\
6 & 1430 & 45 & Female & Anaplastic oligodendrglioma & III \\
\hline
\end{tabular}

Chip platform (Agilent Technologies, Inc.). The RNA concentration ranged from 87.6 to $894.4 \mathrm{ng} / \mu \mathrm{l}$ while the mean RNA integrity number was 7.15 with a standard deviation of 0.46 .

$a C G H$. The DNA obtained from tissue samples were then investigated for genetic aberrations by aCGH using the Cytosure 4x180K oligonucleotide array (Agilent Technologies, Inc.). For each sample, $18 \mu \mathrm{l}$ genomic DNA was used. The CytoSure Genomic DNA aCGH labeling kit (Agilent Technologies, Inc.) was used to label the reference and tumor DNA with Cy-3 and Cy-5 respectively. The labeled targets were then purified according to the manufacturer's protocol with a minimum labeling efficiency of $250 \mathrm{pmol} / \mu \mathrm{g}$ DNA for $\mathrm{Cy} 3$ and $200 \mathrm{pmol} / \mu \mathrm{g}$ DNA for Cy-5. The purified Cy3 and Cy5-labelled genomic DNA was then mixed with human Cot-1 DNA, blocking agent and hybridization buffer, and then was denatured and incubated at $37^{\circ} \mathrm{C}$ for $30 \mathrm{~min}$. A total of $100 \mu \mathrm{l}$ sample mix was then pipetted into the hybridization chamber containing the microarray and placed in a rotisserie hybridization oven at $65^{\circ} \mathrm{C}$ for $40 \mathrm{~h}$. Subsequent to hybridization, the slides were washed with 2 wash buffers, Wash Buffer 1 for $5 \mathrm{~min}$ at room temperature and Wash Buffer 2 for $1 \mathrm{~min}$ at $37^{\circ} \mathrm{C}$. The slides were then scanned using the Agilent DNA scanner to produce the raw image data. This data was further processed using the Agilent Feature Extraction software (Agilent Technologies, Inc.) and the results analyzed with the Cytosure Interpret software v3.4.2 (Agilent Technologies, Inc.).

NGS-RNA quality control, library construction and sequencing. RNA samples were analyzed using deep transcriptome sequencing (Theragen Etex Bio Institute, Suwon, Gyeonggi, South Korea). A total of $1 \mu \mathrm{g}$ total RNA was mixed with oligo dT magnetic beads to enrich for poly(A) mRNA. The purified mRNAs were disrupted into short fragments and cDNAs were synthesized. The cDNAs were subjected to end-repair, poly(A) addition and connected with sequencing adapters using the TruSeq RNA Sample Preparation kit (Illumina, Inc., San Diego, CA, USA). The suitable fragments were purified using the BluePippin 2\% agarose gel cassette (Sage Science, Inc., MA, USA) and were selected as templates for polymerase chain reaction amplification. The final library size and quality were evaluated electrophoretically with an Agilent High Sensitivity DNA kit (Agilent Technologies, Inc.) with fragment sizes between $350-450$ base pairs. The library was then sequenced using an Illumina HiSeq 2500 sequencer (Illumina, Inc.).

\section{Transcriptome data analysis}

Filtering. The quality of reads were checked using the fast QC tool (v.0.10.1) (21) for basic sequence quality score, GC content, $\mathrm{N}$ content, length distribution and duplication levels. Low quality reads were filtered according to the following criteria: Reads containing $>10 \%$ of skipped bases (marked as 'N's), reads containing $>40 \%$ of bases whose quality scores were $<20$ and reads whose mean quality scores for each read was $<20$. The entire filtering process was performed using in-house scripts.

Sequence alignment. Filtered reads were mapped to the human reference genome (obtained from the online genome database Ensembl release 72) (22) using the aligner Tophat (23).

Gene expression estimation. Gene expression levels were measured using Cufflinks v2.1.1 (24,25) using the gene annotation database of Ensembl release 72. Non-coding gene regions were removed using the mask option. In order to improve the accuracy of measurements, multi-read and fragment bias corrections were applied. All other options were set to default values.

\section{Results}

$a C G H$. aCGH was performed on 3 oligodendroglioma samples, 1 of which was a low-grade oligodendroglioma (WHO Grade II; sample 1090) and 2 anaplastic oligodendroglioma (WHO Grade III; samples 193 and 1395). The purpose of this was to determine any known and novel amplifications and/or deletions in any of the chromosomes in these samples. Figs. 1-3 present the chromosomal aberrations, particularly the amplifications and deletions present in all 3 samples. Sample 1395 , by far, had the greatest number of chromosomal aberrations and sample 193 had the greatest number of deletions out of the 3 samples.

The most common and notable losses were identified on the $1 \mathrm{p}$ chromosomal arm, which was present in all 3 samples. This was followed by a loss in chromosome $19 \mathrm{q}$ present only in the 2 anaplastic oligodendroglioma samples and a whole set of amplification on chromosome 7 present in samples 1395 and 1090. In addition, there was a partial loss in chromosome 14q (samples 193 and 1395) and deletions in chromosomes 15q (in samples 1395 and 1090). It was interesting to note that while there was a deletion in chromosome $17 \mathrm{p}$ in samples 1395 and 1090, sample 1395 had an extra mutation in the form of amplification on chromosomal arm 17q. Another interesting 


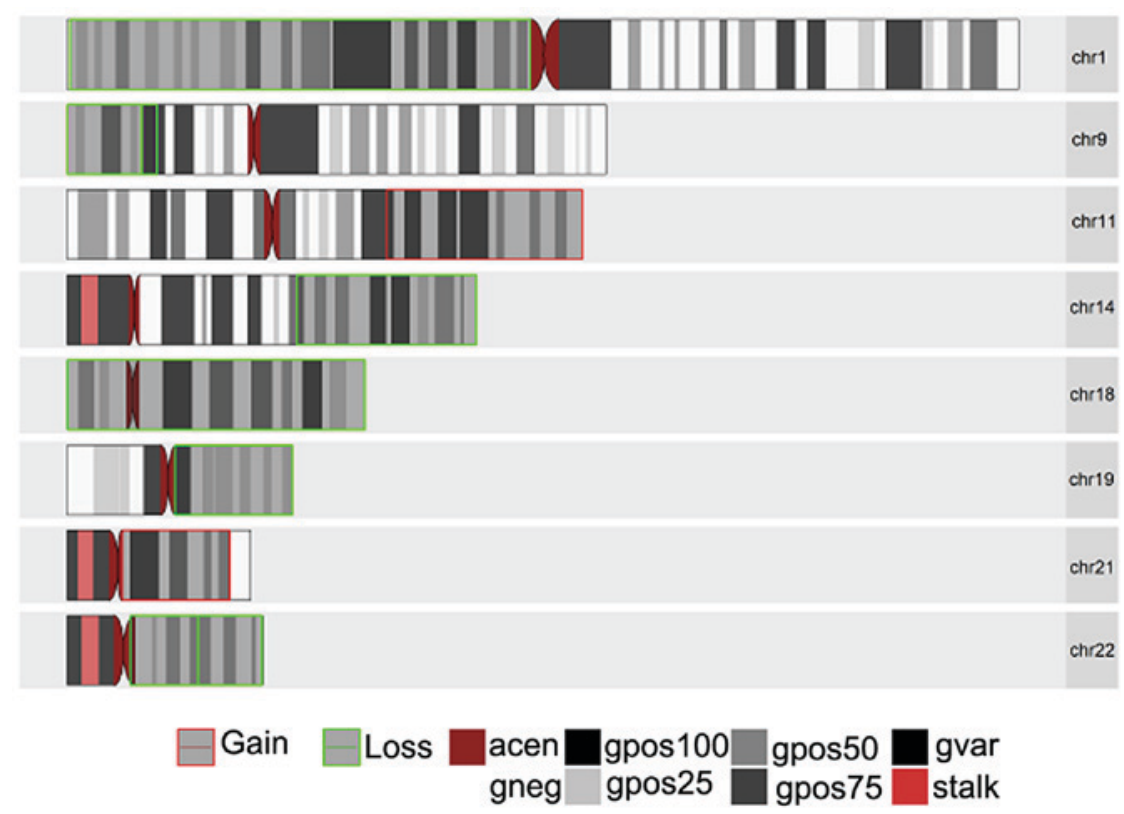

Figure 1. Ideogram for aCGH analysis for sample 193 (anaplastic oligodendroglioma) showing chromosomal aberrations in the form of amplification/gain and/or deletion/loss in the chromosomes. aCGH, array comparative genomic hybridization.

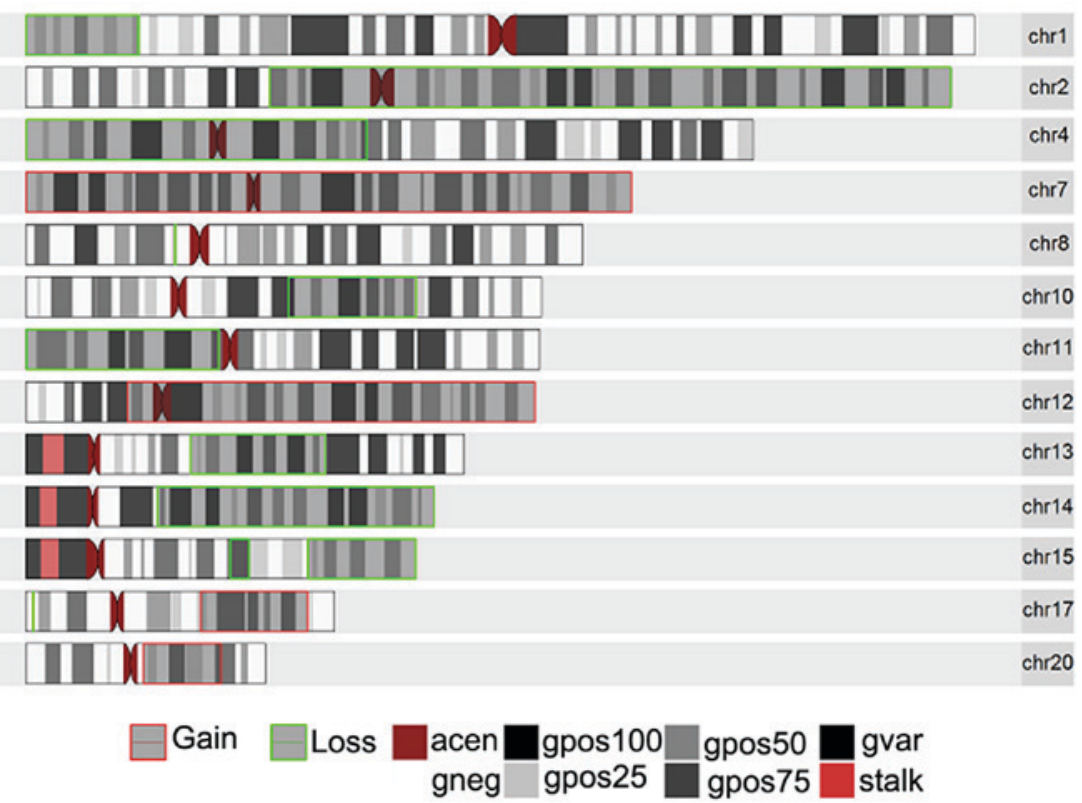

Figure 2. Ideogram for aCGH analysis for sample 1395 (anaplastic oligodendroglioma) showing chromosomal aberrations in the form of amplification/gain and/or deletion/loss in the chromosomes. aCGH, array comparative genomic hybridization.

result was observed on chromosome 11 for samples 193 and 1395 with a partial amplification in the q arm for sample 193 and a complete deletion of the $\mathrm{p}$ arm in sample 1395 .

Less common losses were also observed in chromosomes 2p, 2q, 4p, 4q, 8p, 9p, 10q, 13q, 18 (whole chromosomal arm) and $22 \mathrm{q}$. Excluding chromosomes $7,11 \mathrm{q}$ and $17 \mathrm{q}$, losses were also identified in chromososmes 12p, 12q, 20q and 21q.

Copy number variations (CNVs) in anaplastic oligodendroglioma. Using aCGH for the genome-wide profiling of oligodendroglioma not only revealed chromosomal alterations within the tumor samples, but also allowed for the detection of genomic CNVs. Based on the examination of sample 193, notable deletions in the majority of the chromosomes associated with amplifications were identified in the tumor sample. Chromosome $1 \mathrm{p}$ contained the largest loss in its chromosomal arm of $120.63 \mathrm{Mb}$ involving 2540 gene overlaps. This was followed by chromosome $19 \mathrm{q}$ with a deletion of 1599 overlapping genes. Notable losses were also observed on chromosomes 9p, 14q, 18, 19q and 22q with deletions of 303,1172, 1032, 1599 and 1129 overlapping genes, respectively. There were an additional 918 genes that were amplified on chromosome $11 \mathrm{q}$ and 484 genes amplified on chromosome 21q. 


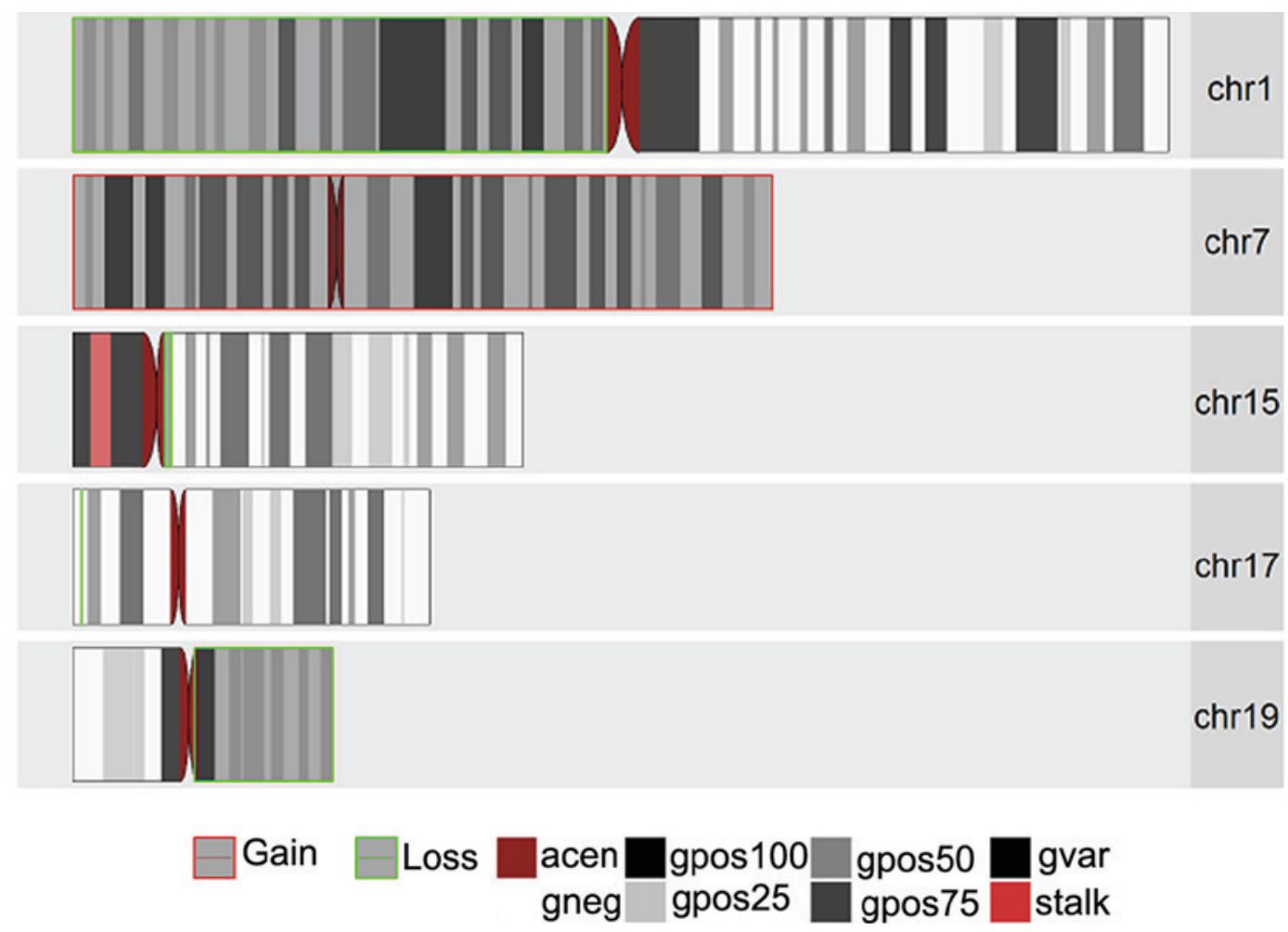

Figure 3. Ideogram for aCGH analysis for sample 1090 (low grade oligodendroglioma) showing chromosomal aberrations in the form of amplification/gain and/or deletion/loss in the chromosomes. aCGH, array comparative genomic hybridization.

Two anaplastic oligodendroglioma samples (samples 193 and 1395) were compared to determine if there were any $\mathrm{CNV}$ overlaps. The two samples had a common CNV at the same start and stop positions (10478 and 121350692). Sample 1395 had a matching region deleted that spanned 29663113 base pairs in chromosome 1 , a matching region that was amplified spanning 159022882 base pairs on chromosome 7 and another matching deleted region spanning 1087 base pairs on chromosome 17. For sample 193, there was a matching region of 120627374 base pairs that was deleted in chromosome 1 and another region of 30856201 base pairs that was deleted on chromosome 19.

Gene ontology. A number of gene functions linked to the chromosomal aberrations in the tumor cells were selected, particularly with regards to immune regulation. This included deletions in genes involved in the regulation of type I interferon-mediated signaling pathway, T-cell activation, complement activation of the classical pathway, circulating immunoglobulin complexes, immunoglobulin receptor binding and antigen binding. The genes involved in the amplification of certain chromosomes were not as common, however they included functions in the regulation of interleukin- $1 \beta$ secretion, keratinization, cell-cell junction, intermediate filament and endopeptidase activity. All overlapping genes involved in chromosomal aberrations (amplifications/deletions) are listed in Table II.

$N G S$. High-throughput RNA sequencing was performed on all 6 oligodendroglioma samples. The NGS analysis of sample 193 only revealed a few notable gene fusions. Data revealed five novel fusion genes (Fig. 4). Intra-chromosomal rearrangements were identified on chromosome 1q42.3 between the AT-rich interaction domain 4B (ARID4B) and G protein subunit $\gamma$ 4 (GNG4) genes (Fig. 5), chromosome 11q12.1 between the family with sequence similarity 111 member B (FAM111B) and FAM111 A genes (Fig. 6) and on chromosome 16p13.3 between the WD repeat domain 90 (WDR90) and ras homolog family member T2 (RHOT2) genes (Fig. 7). Inter-chromosomal rearrangements were identified between genes LDL receptor related protein 12 (LRP12; on chromosome 8q22.3) and parkin RBR E3 ubiquitin protein ligase (PARK2; on chromosome 6q26; Fig. 8) and additionally between genes neurofibromin 1 (NF1) and SH3 domain containing GRB2 like 3, endophilin A3 (SH3GL3) which mapped to chromosomes 17q11.2 and 15q25.2, respectively (Fig. 9).

The fusion events occurring in the majority of the chromosomes in Sample 193 appeared to have different activity levels. For the ARID4B_GNG4 fusion gene, the activity for GNG4 was higher compared with ARID4B. This was also observed in the FAM111B_FAM111A gene fusion where the activity of the FAM111A isoform was higher compared with the FAM111B isoform. The most notable difference in activity was observed in the fusion genes WDR90_RHOT2 and NF1_ SH3GL3, where RHOT2 and NF1 activity were substantially higher compared with their respective pairings. On the other hand, there was no notable difference in the activity for the fusion gene pair LRP12_PARK2.

\section{Discussion}

In the present study, a comparative genomic analysis of oligodendroglioma (WHO Grade II) and anaplastic oligodendroglioma (WHO Grade III) samples was undertaken, using 
Table II. GO associated with chromosomal aberrations.

A, List of overlapping genes involved in loss/deleted regions

\begin{tabular}{|c|c|c|c|c|}
\hline GO category & GO name & No. of genes & P-value & Term ID \\
\hline $\mathrm{BP}$ & Regulation of type I interferon-mediated signaling pathway & 18 & $1.68 \times 10^{-04}$ & GO:0060338 \\
\hline $\mathrm{BP}$ & T-cell activation involved in immune response & 24 & $2.72 \times 10^{-02}$ & GO:0002286 \\
\hline $\mathrm{BP}$ & Defense response to other organisms & 94 & $3.46 \times 10^{-06}$ & GO:0098542 \\
\hline $\mathrm{BP}$ & $\begin{array}{l}\text { Positive regulation of peptidyl-serine phosphorylation of } \\
\text { signal transducer and activator of transcription protein }\end{array}$ & 17 & $8.33 \times 10^{-11}$ & GO:0033141 \\
\hline $\mathrm{BP}$ & Response to exogenous double stranded RNA & 19 & $5.93 \times 10^{-05}$ & GO:0043330 \\
\hline $\mathrm{BP}$ & Complement activation, classical pathway & 67 & $3.01 \times 10^{-29}$ & GO:0006958 \\
\hline $\mathrm{CC}$ & Extracellular region & 569 & $2.73 \times 10^{-3}$ & GO:0005576 \\
\hline $\mathrm{CC}$ & Blood microparticle & 50 & $9.79 \times 10^{-08}$ & GO:0072562 \\
\hline $\mathrm{CC}$ & Immunoglobulin complex, circulating & 37 & $9.21 \times 10^{-22}$ & GO:0042571 \\
\hline $\mathrm{CC}$ & External side of plasma membrane & 52 & $9.21 \times 10^{-3}$ & GO:0009897 \\
\hline MF & Metal ion binding & 489 & $7.15 \times 10^{-4}$ & GO:0046872 \\
\hline MF & Immunoglobulin receptor binding & 37 & $1.76 \times 10^{-20}$ & GO:0034987 \\
\hline MF & Transcription factor activity, sequence-specific DNA binding & 189 & $1.12 \times 10^{-06}$ & GO:0003700 \\
\hline MF & DNA binding & 343 & $5.49 \times 10^{-09}$ & GO:0003677 \\
\hline MF & Type I interferon receptor binding & 16 & $3.25 \times 10^{-12}$ & GO:0005132 \\
\hline MF & Antigen binding & 92 & $1.98 \times 10^{-39}$ & GO:0003823 \\
\hline MF & Serine-type endopeptidase activity & 55 & $3.41 \times 10^{-05}$ & GO:0004252 \\
\hline
\end{tabular}

B, List of overlapping genes involved in gain/amplified regions

\begin{tabular}{|c|c|c|c|c|}
\hline GO category & GO name & No. of genes & P-value & Term ID \\
\hline $\mathrm{BP}$ & Regulation of interleukin- $1 \beta$ secretion & 9 & $4.61 \times 10^{-4}$ & GO:0050706 \\
\hline $\mathrm{BP}$ & Keratinization & 30 & $3.95 \times 10^{-11}$ & GO:0031424 \\
\hline $\mathrm{BP}$ & Multicellular organismal catabolic process & 10 & $3.23 \times 10^{-2}$ & GO:0044243 \\
\hline $\mathrm{CC}$ & Cell-cell junction & 26 & $2.65 \times 10^{-2}$ & GO:0005911 \\
\hline $\mathrm{CC}$ & Intermediate filament & 33 & $2.45 \times 10^{-15}$ & GO:0005882 \\
\hline MF & Odorant binding & 11 & $1.56 \times 10^{-2}$ & GO:0005549 \\
\hline $\mathrm{MF}$ & Endopeptidase activity & 30 & $4.07 \times 10^{-3}$ & GO:0004175 \\
\hline MF & Interleukin-10 receptor activity & 4 & $1.50 \times 10^{-2}$ & GO:0004920 \\
\hline
\end{tabular}

GO, gene ontology; BP, biological process; CC, cellular component; MF, molecular function.

aCGH and NGS. The aCGH results revealed that the most common deletion present in oligodendroglioma samples were on chromosomes $1 \mathrm{p}$ followed by $19 \mathrm{q}$. This is in keeping with previous studies that have presented similar results $(26,27)$. This is not surprising as LOH 1p 19q is a predictor of radio- and chemosensitivity in patients with improved survival $(28,29)$.

Aberrations were identified in the majority of the other chromosomes and included amplification/gain or deletion/loss. This reiterates the fact that genetic alterations are common in solid tumor types, including tumors of the central nervous system (30-32).

Genetic alterations including CNVs are more commonly observed in high-grade tumor types compared with low-grade tumor types (33). Comparison between 2 anaplastic oligodendroglioma samples, namely samples 1395 and 193, revealed that there was a large region of $\mathrm{CNV}$ overlap of $>121$ million base pairs. This suggests that high-grade tumor types originating from a similar cell type have not only heterogeneity but also substantial homogeneity.

Gene ontology analysis of the gene functions associated with the chromosomal aberrations in the tumor cells indicate that a large number of these genes are involved in the innate and adaptive immune system. This included deletions in genes involved in the regulation of the type I interferon-mediated signaling pathway, T-cell activation, complement activation of the classical pathway, circulating immunoglobulin complexes, immunoglobulin receptor binding and antigen binding. This suggests that the modulation of the immune system serves a critical role in tumor response.

NGS analysis revealed 5 novel fusion genes in sample 193 (anaplastic oligodendroglioma). To the best of our knowledge, this is the first study to have identified the presence of 5 novel 


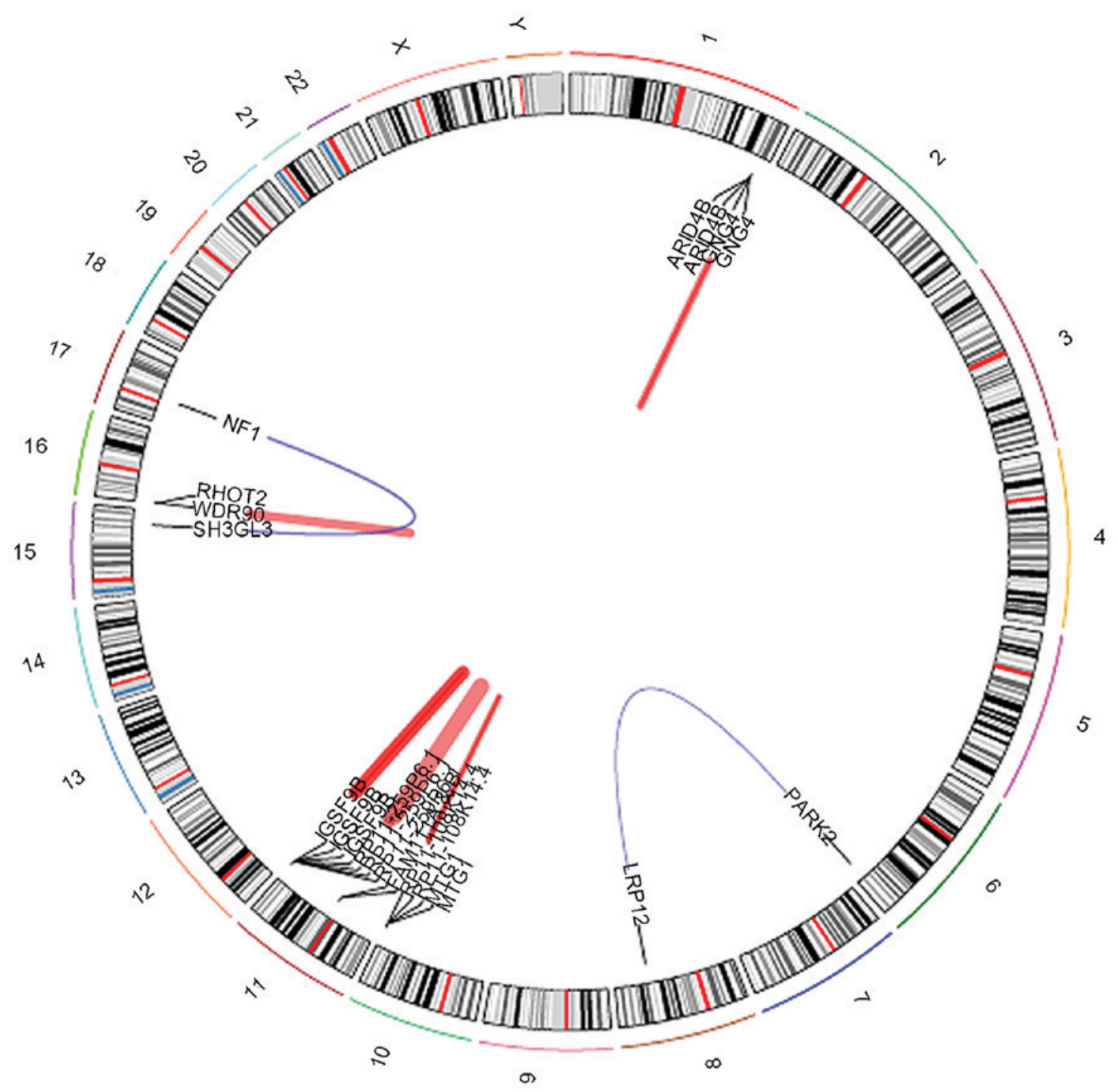

Figure 4. Fusion gene map showing fusion of genes in sample 193.

fusion genes in one anaplastic oligodendroglioma sample with 3 intra-chromosomal and 2 inter-chromosomal fusions. Fusion genes are not uncommon in gliomas. The fibroblast growth factor receptor 3_transforming acidic coiled-coil containing protein 3 gene present in patients with glioblastoma has been revealed to recur at a rate of up to $8.3 \%$. It is postulated to be involved in the extracellular signal-regulated kinase (ERK) and signal transducer and activator of transcription 3 (STAT3) signaling pathways, promoting tumor growth and formation $(34,35)$. Another fusion gene that is common is KIAA1549_B-Raf proto-oncogene, serine threonine kinase (BRAF) which occurs in $70 \%$ of patients diagnosed with pilocytic astrocytoma. A mutation in the BRAF gene has been observed in a number of cancer types, and is not exclusive to gliomas (36).

The 3 intra-chromosomal fusions identified were ARID4B_GNG4, FAM111B_FAM111A and WDR90_ RHOT2. ARID4B, also known as retinoblastoma-binding protein-1-like protein-1 or breast cancer-associated antigen 1, belongs to the ARID gene family and is frequently expressed in human carcinomas and normal testis (37). The gene family is involved in regulating cell growth and mutations result in the loss of inhibitory histone makers and DNA methylation (38). ARID4B in particular serves a dual role in a tumor, where it contributes to the spread and invasive nature of breast cancer cells; however, it also functions as a tumor suppressor in leukemia $(39,40)$. It has recently been reported to be overexpressed in primary brain tumor types and therefore may be able to function as an effective biomarker for and predictor of tumor grade in meningioma and gliomas (41). GNG4, on the other hand, was recently discovered to be hypermethylated and downregulated in GBM (42). It has been suggested that it may function as a tumor suppressor gene in GBM through the inhibition of the $\mathrm{C}-\mathrm{X}-\mathrm{C}$ motif chemokine ligand $12 / \mathrm{C}-\mathrm{X}-\mathrm{C}$ motif chemokine receptor 4-dependent chemokine signaling pathway (42). Therefore, it is likely that a fusion between the ARID4B and GNG4 genes has a role in the signaling pathway that regulates DNA methylation.

FAM111B and FAM111A are members of the FAM111 family of genes. Although the two genes contain a functional region called a trypsin-like peptidase domain located close to each other, they each have distinct functional properties (43). A mutated form of FAM111B protein is thought 


\section{Chromosome 1

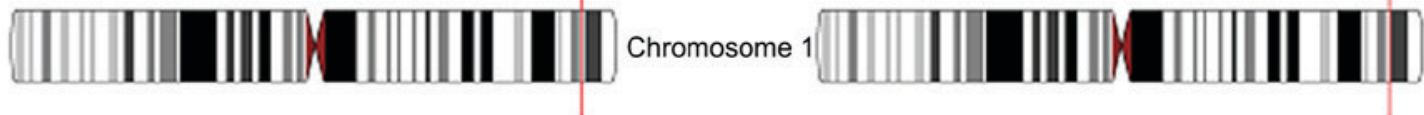

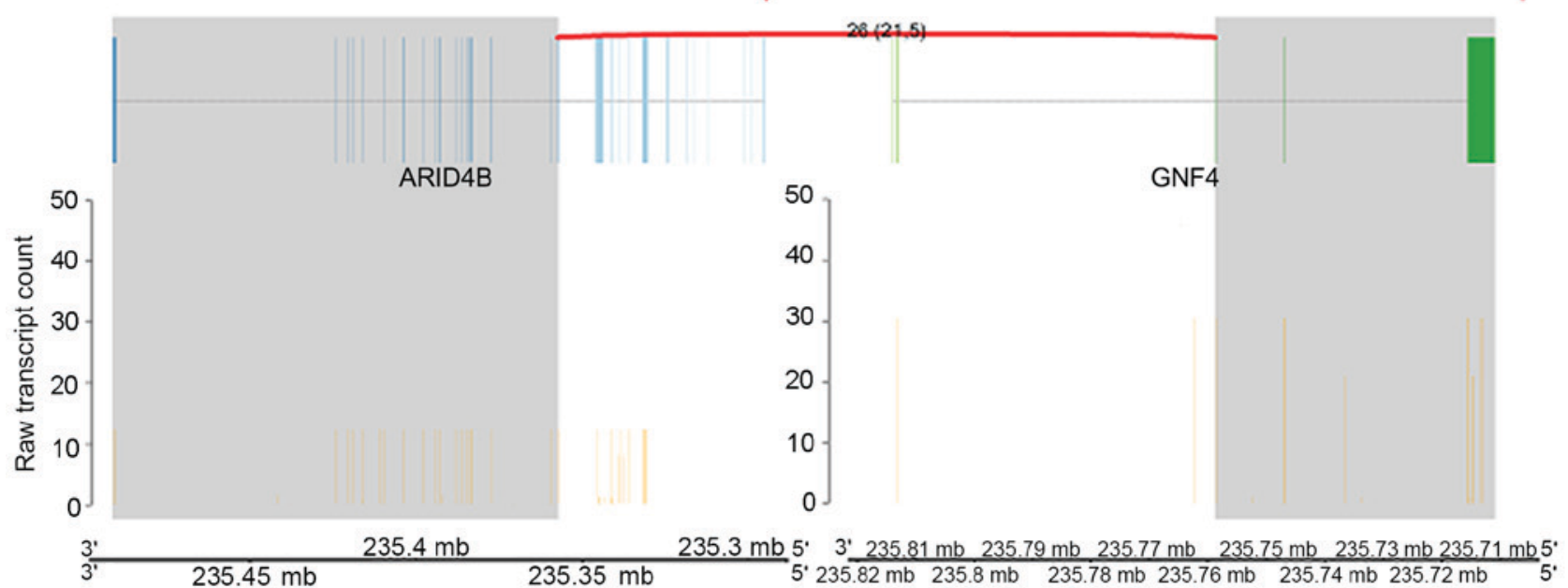

Figure 5. Chromosomal view of intra-chromosomal fusion gene ARID4B_GNG4 and its genomic activity for sample 193.

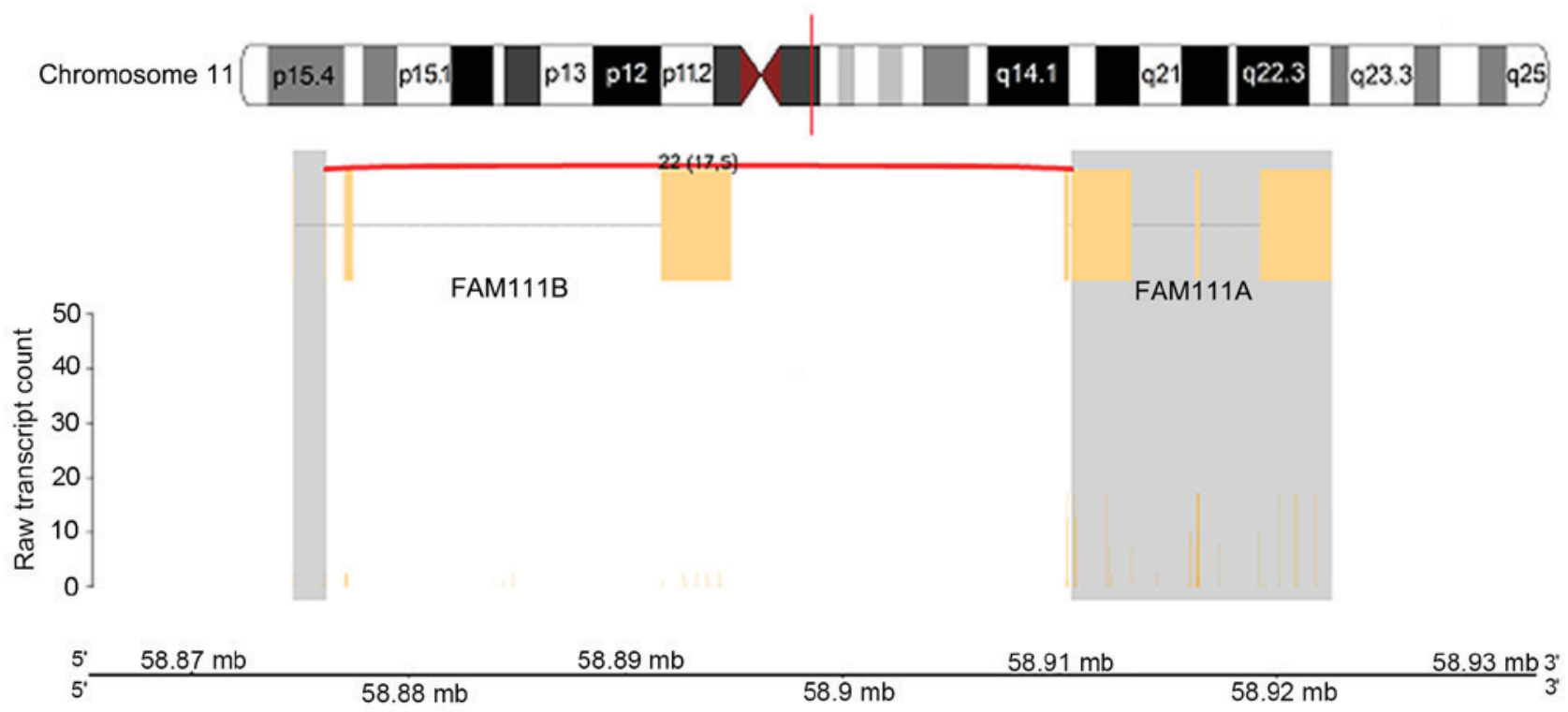

Figure 6. Chromosomal view of intra-chromosomal fusion gene FAM111B_FAM111A and its genomic activity for sample 193.

to be involved in hereditary fibrosing poikiloderma, characterised by mottled pigmentation, telangiectasia and atrophy of the epidermis, tendon contractors and progressive pulmonary fibrosis (43). Notably, it has also been reported to be a cancer predisposition gene to pancreatic cancer although a broader analysis and exploration is required to confirm this (44). FAM111A is the paralog of this gene and is associated with the diseases Kenny-Caffey syndrome type 2 and osteocraniostenosis (45). It may also contribute to carcinogenesis as it serves a role in cell cycle regulation and DNA replication.

The activity of WDR90 was downregulated when fused with RHOT2 in the anaplastic oligodendroglioma sample. WDR90 has been thought to serve a role in signal transduction, transcription regulation, cell cycle control, autophagy and apoptosis (46). However, RHOT2 was upregulated in the tumor sample in the present study. The RHOT2 gene is part of the Ras homolog gene family and encodes an enzyme called mitochondrial Rho GTPase 2 (47). The enzyme is thought to serve a role in mitochondrial trafficking and apoptosis $(47,48)$. RHOT2 has also been linked to cancer progression, as it is upregulated in epithelial and hematological tumor types (49). This may corroborate with the hypothesis that an increase in RHOT2 may serve a role in supporting tumor cell invasion in high-grade gliomas.

LRP12 encodes a protein named as the 12th member of the low-density lipoprotein receptor related protein family. Lipoproteins serve an important role in the development of the brain. The low-density lipoprotein LRP12 has been postulated to be a receptor for internalizing lipophilic molecules and 

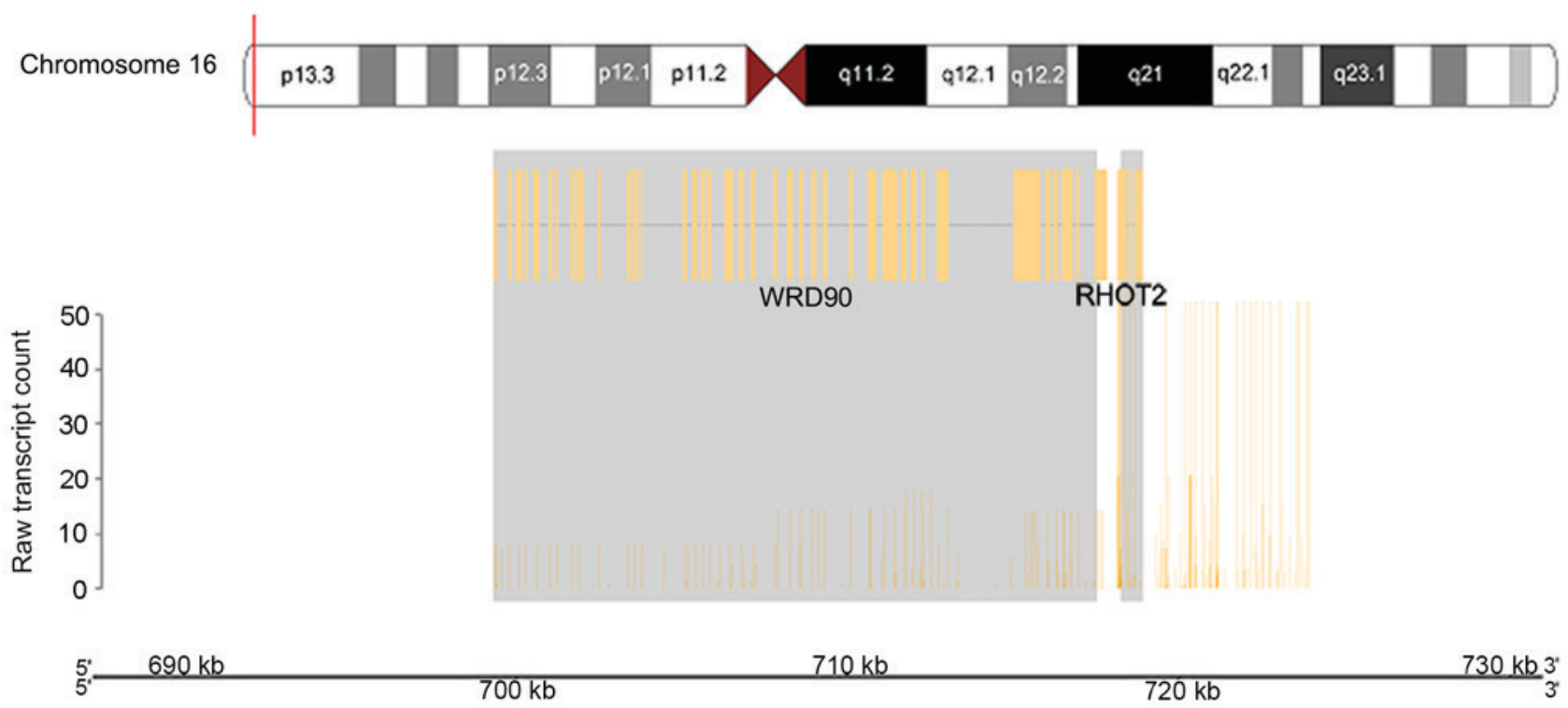

Figure 7. Chromosomal view of intra-chromosomal fusion gene WDR90_RHOT2 and its genomic activity for sample 193.
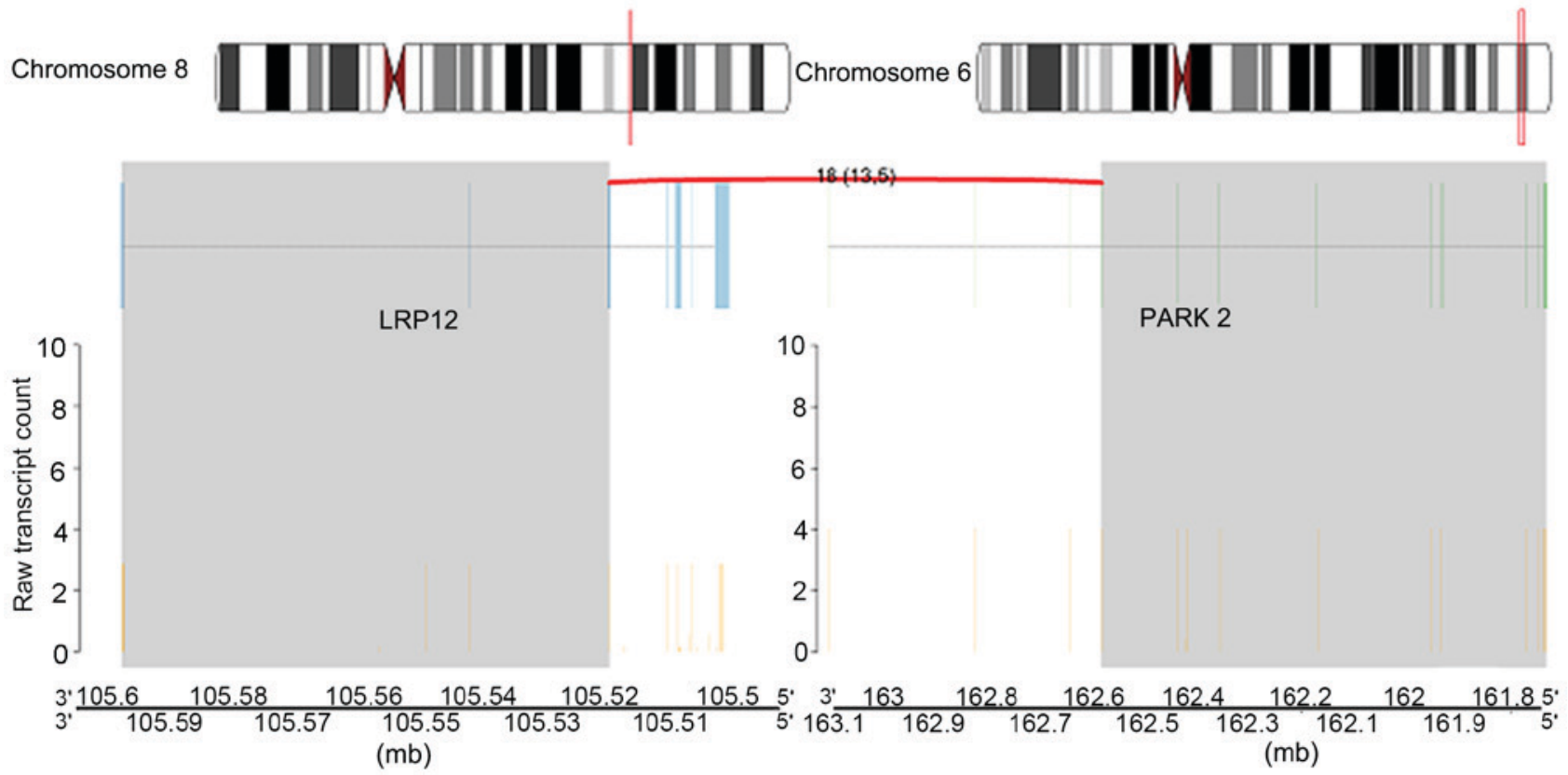

Figure 8. Chromosomal view of inter-chromosomal fusion gene LRP12_PARK2 and its genomic activity for sample 193.

may have a potential function in signal transduction (50). Also known as suppressor of tumorigenicity 7 protein, LRP12 has also been reported to be differentially expressed in various cancer types including oral squamous cell carcinoma (50), lymphoma (51) and more recently gangliogliomas and low-grade central nervous system tumor types (52). PARK2 is a tumor suppressor gene and when deleted is known to promote tumorigenicity. The activation of PARK2 and its function in tumor growth is not fully understood. However, the anti-apoptotic protein B-cell lymphoma-extra large is thought to be involved to some extent in the activation mechanism of PARK2 through regulation of the permeability of the mitochondrial outer membrane (53). The fusion between these two genes may imply the same manner by which high-grade gliomas including anaplastic oligodendroglioma progress, although further investigation is required in order to justify this.

The most notable fusion gene was NF1_SH3GL3. The NF1 gene is located on chromosome 17q11.2 and encodes the cytoplasmic and multi-domain regions of neurofibromin, a protein that functions as a tumor suppressor and negatively regulates Ras through the mitogen-activated protein kinase (MAPK)- and mechanistic target of rapamycin-pathway (54). A mutation or inactivation of the gene will likely increase Ras activity (55). Ras activation will induce a series of cascades involved in regulating transcription, translation, cell cycle progression, metabolic processes, immune inflammatory responses and survival. 

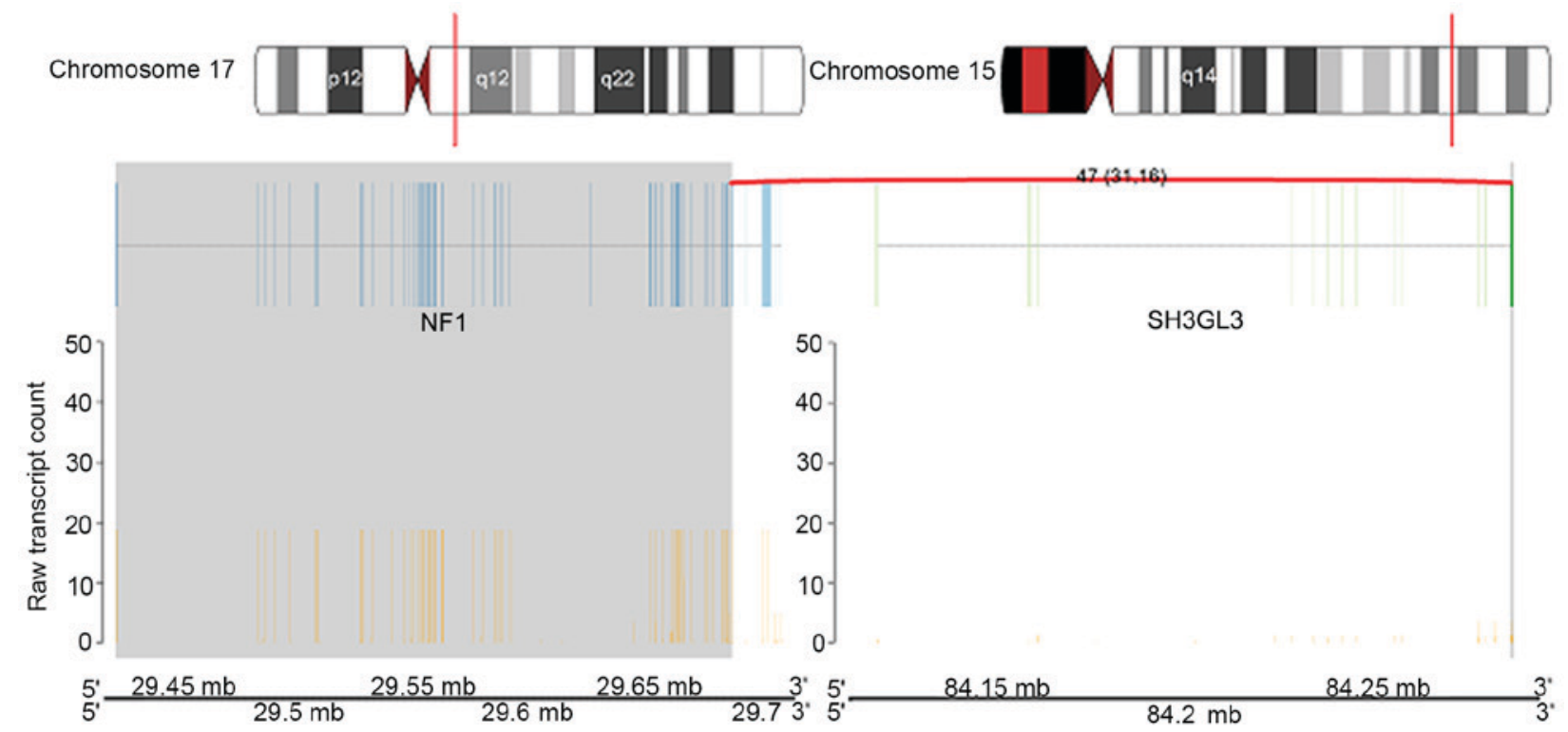

Figure 9. Chromosomal view of inter-chromosomal fusion gene NF1_SH3GL3 and its genomic activity for sample 193.

NF1 mutations are mostly identified in low-grade gliomas, particularly with regards to the optic pathway (56). However the mutation may also be observed in higher-grade gliomas commonly during adult life (57). In the majority of cases, there are mutations that occur in additional genes together with NF1, including TP53 and cyclin dependent kinase inhibitor $2 \mathrm{~A}(58,59)$. This is clearly observed in the anaplastic oligodendroglioma sample 193 that has multiple gene amplifications and deletions, along with gene fusions in different chromosomes.

Currently, there are 5 known NF1 fusion genes based on The Cancer Genome Atlas RNA-Seq analysis data that are involved in certain cancer types including oesophageal carcinoma, lung adenocarcinoma and ovarian cancer (60). Based on the Ensembl genome browser, there are 23 alternative transcripts that have been discovered from gene splicing. However, the full significance of the NF1 alteration has yet to be elucidated for this particular glioma subtype and requires further study. One previous report revealed a linkage between NF1 gains in a subset of diffuse gliomas, whilst NF1 loss is restricted to only a small subset of GBM (60). In the case of anaplastic oligodendroglioma, there has only been one case report that suggested an association between a somatic mutation in NF1 and the tumor (61).

The SH3GL3 gene is a member of a family of genes highly expressed in the central nervous system (62). More specifically, the gene becomes enriched in myelinating and newly formed oligodendrocytes. The carboxyl and amino-terminal of the Src-homology-3 domain (SH3) binds to proline-rich ligands and is involved in signal transduction pathways for protein-protein interaction. The disease most frequently associated with the SH3GL3 gene is Huntington's disease (HD) (63). The SH3 domain binds to the proline-rich region in the first exon of the HD gene, which contributes to the production of high levels of insoluble polyglutamine-containing aggregates in the brain. These aggregates interfere with cellular functions, resulting in cellular death and neuronal degradation that are atypical in HD (63). SH3GL3 mutations have been implicated in a number of cancer types including colorectal cancer, multiple myeloma and breast cancer (64-66). Recently, it has been suggested that SH3GL3 is one of three novel genes expressed in infiltrating glioma cells and is likely a key component involved in the invasive nature of malignant gliomas (67).

The growth factor receptor bound protein (GRB2), via its SH3 domain, serves a key role in the Ras/MAPK pathway. GRB2 facilitates Ras activation via the co-localisation of SOS Ras/Rac guanine nucleotide exchange factor 1 and Ras, which in turn activates MAPK/e mitogen-activated protein kinase (MEK). This then activates MAPK/ERK phosphorylation through Raf activation, promoting cell proliferation and survival (68). A mutation or deletion/amplification in part of the SH3 domain or GRB2 adaptor protein would affect the Ras/Raf/MEK/ERK cascade, affecting cellular responses including cell cycle progression and potentially contributing to the spread of solid tumor types through local invasion and metastasis, for example in oligodendroglioma. Its signaling has been reported to be linked with several human diseases including breast cancer and chronic myelogenous leukaemia (36).

Another paralogous gene, SH3GL2, has already been reported to be downregulated in glioblastoma cells (69). Loss of SH3GL2 may increase the activity of STAT3/matrix metalloproteinase- 2 signaling and promote the migration and invasion of high-grade glioma cells. It may be fused to a part of the $\mathrm{SH} 3$ domain of GRB2, similar to the interaction between NF2 and GRB2 signaling in neurofibromatosis type 2 (70). However, it still remains to be seen how the interaction between NF1 and SH3GL3 may define a particular glioma cell type, for example anaplastic oligodendroglioma.

In the present study, five novel fusion transcripts were identified, the most notable of which was the identification of the NF1_SH3GL3 fusion gene in an anaplastic oligodendroglioma sample. To the best of our knowledge, this is the first report of its type to identify the involvement of these five fusion genes in the pathogenesis of oligodendroglioma. The functional consequences of these fusions and their underlying mechanisms have yet to be explored and require further investigation and validation. 


\section{Acknowledgements}

The authors would like to thank Mr Ranganth Gudimella (Sengenics, Kuala Lumpur, Malaysia) for help with the bioinformatics and database analysis, Dr Zubaidah Zakaria (Cancer Research Center, Institute for Medical Research) for helpful comments and suggestions, the Brain Tumor Foundation of Canada for providing some of the tissue samples, and the Director General of Health Malaysia for permission to publish this study.

\section{Funding}

The present study was supported by the Ministry of Health Malaysia (grant no. NMRR-14-599-19912) awarded to Dr Stephen Navendran Ponnampalam.

\section{Availability of data and materials}

The datasets used and/or analyzed during the current study are available from the corresponding author on reasonable request.

\section{Authors' contribution}

SAH performed the majority of the experimental work. SNP provided substantial contributions to the conception and design of the study, coordinated the project and revised the manuscript critically for important intellectual content. MNA performed some of the experimental work.

\section{Ethical approval}

The present study received ethical approval from the Medical Research Ethics Council of the Ministry of Health Malaysia on 6th August 2014 [approval no. (6) KKM/NIHSEC/P14-679] and was renewed annually until October 2016.

\section{Patient consent for publication}

All subjects involved in the present study provided written informed consent to participate in this study.

\section{Competing interests}

The authors declare that they have no competing interests.

\section{References}

1. Stewart BW and Wild CP, (eds): World cancer report 2014. International agency for research on cancer (IARC) Publications, Lyon, France, 2014 (http://www.iarc.fr/en/publications/books/wcr/index.php; accessed on 20/01/2018).

2. Ferlay J, Soerjomataram I, Ervik M, Dikshit R, Eser S, Mathers C, Rebelo M, Parkin DM, Forman D and Bray F: GLOBOCAN 2012 v1.0, Cancer incidence and mortality worldwide. IARC CancerBase no.11, IARC Press, Lyon, 2013.

3. US Mortality Data: 2006. National Centre for Health Statistics. Centres for Disease Control and Prevention, 2009.

4. Louis DN, Ohgaki H, Wiestler OD, Cavenee WK, Burger PC, Jouvet A, Scheithauer BW and Kleihaus P: The 2007 WHO classification of tumors of the central nervous system. Acta Neuropathol 114: 97-109, 2007.

5. Zhang X,Zhang W, Cao WD, Cheng G and Zhang YQ: Glioblastoma multiforme: Molecular characterization and current treatment strategy (Reviw). Exp Ther Med 3: 9-14, 2012.
6. Li J, Miao N, Liu M, Ciu W, Liu X, Shi X, Qing S, Ma Y, Zhang $\mathrm{W}$ and Biekemituofu H: Clinical significance of chromosome $1 \mathrm{p} / 19 \mathrm{q}$ loss of heterozygosity and Sox 17 expression in oligodendrogliomas. Int J Clin Exp Pathol 7: 8609-8615, 2014.

7. Kakkar A, Suri V, Jha P, Srivasta A, Sharma V, Pathak P, Sharma MC, Sharma MS, Kale SS, Chosdol K, et al: Loss of heterozygosity on chromosome $10 \mathrm{q}$ in glioblastomas, and its association with other genetic alterations and survival in Indian patients. Neurol India 59: 254-261, 2011.

8. Hartmann C, Hentschel B, Tatagiba M, Schramm J, Schnell O, Seidel C, Stein R, Reifenberger G, Pietsch T, von Deimling A, et al: Molecular markers in low-grade gliomas: Predictive or prognostic? Clin Cancer Res 17: 4588-4599, 2011.

9. Burger PC, Minn AY, Smith JS, Borell TJ, Jedlicka AE, Huntley BK, Goldthwaite PT, Jenkins RB and Feuerstein BG: Losses of chromosomal arms $1 \mathrm{p}$ and $19 \mathrm{q}$ in the diagnosis of oligodendroglioma. A study of paraffin-embedded sections. Mod Pathol 14: 842-853, 2001.

10. Haynes HR, Camelo-Piragua S and Kurian KM: Prognostic and predictive biomarkers in adult and pediatric gliomas: Toward personalized treatment. Front Oncol 4: 47, 2014.

11. Gadji M, Fortin D, Tsanaclis AN and Drouin R: Is the $1 \mathrm{p} / 19 \mathrm{q}$ deletion a diagnostic marker of oligodendrogliomas? Cancer Genet Cytogenet 194: 12-22, 2009.

12. Hartmann C, Meyer J, Balss J, Capper D, Mueller W, Christians A, Felsberg J, Wolter M, Mawrin C, Wick W, et al: Type and frequency of IDH1 and IDH2 mutations are related to astrocytic and oligodendroglial differentiation and age: A study of 1,010 diffuse gliomas. Acta Neuropathol 118: 469-474, 2009.

13. Nayak A, Ralte AM, Sharma MC, Singh VP, Mahapatra AK, Mehta VS and Sarkar C: p53 protein alterations in adult astrocytic tumors and oligodendrgliomas. Neurol India 52: 228-232, 2004.

14. Blakely J and Grossman S: Anaplastic oligodendroglioma. Curr Treat Options Neurol 10: 295-307, 2008.

15. Mohapatra G, Betensky RA, Miller ER, Carey B, Gaumont LD, Engler DA and Loius DN: Glioma test array for use with formalin-fixed, paraffin-embedded tissue: Array comparative genomic hybridization correlates with loss of heterozygosity and fluorescence in situ hybridization. J Mol Diagn 8: 268-276, 2006.

16. Meyerson M, Gabriel S and Getz G: Advances in understanding cancer genomes through second-generation sequencing. Nat Rev Genet 11: 685-696, 2010.

17. Robinson K: Application of second-generation sequencing to cancer genomics. Brief Bioinform 11: 524-534, 2010.

18. Patil V, Pal J and Somasundaram K: Elucidating the cancer-specific genetic alteration spectrum of glioblastoma derived cell lines from whole exome and RNA sequencing. Oncotarget 6: 43452-43471, 2015.

19. Zhang Y, Chen K, Sloan SA, Bennet ML, Scholze AR, O'Keefe S, Phatnani HP, Guarnieri P, Caneda C, Ruderisch N, et al: An RNA-sequencing transcriptome and splicing database of glia, neurons, and vascular cells of the cerebral cortex. J Neurosci 34: 11929-11947, 2014.

20. Zhao Z, Meng F, Wang W, Wang Z, Zhang C and Jiang T: Comprehensive RNA-seq transcriptomic profiling in the malignant progression of gliomas. Sci Data 4: 170024, 2017.

21. Andrews S: FastQC: A quality control tool for high throughput sequence data. Available online at: http://www.bioinformatics. babraham.ac.uk/projects/fastqc, accessed on 15/06/2017.

22. Flicek P, Ahmed I, Amode MR, Barrell D, Beal K, Brent S, Carvalho-Silva D, Clapham P, Coates G, Fairley S, et al: Ensembl 2013. Nucleic Acids Res 41 (Database Issue): D48-D55, 2013.

23. Trapnell C, Pachter L and Salzberg SL: Tophat: Discovering splice junctions with RNA-Seq. Bioinformatics 25: 1105-1111, 2009.

24. Trapnell C, Roberts A, Goff L, Pertea G, Kim D, Kelley DR, Pimentel H, Salzburg SL, Rinn JL and Pachter L: Differential gene and transcript expression analysis of RNA-seq experiments with TopHat and Cufflinks. Nat Protoc 7: 562-578, 2012.

25. Trapnell C, Williams BA, Pertea G, Mortazavi A, Kwan G, van Baren MJ, Salzburg SL, Wold BJ and Pachter L: Transcript assembly and quantification by RNA-Seq reveals unannotated transcripts and isoform switching during cell differentiation. Nat Biotechnol 28: 511-515, 2010.

26. Bello MJ, Vaquero J, de Campos JM, Kusak ME, Sarasa JL, Saez-Castresana J, Pestana A and Rey JA: Molecular analysis of chromosome 1 abnormalities in human gliomas reveals frequent loss of 1p in oligodendroglial tumors. Int J Cancer 57: 172-175, 1994. 
27. Bello MJ, Leone PE, Vaquero J, de Campos JM, Kusak ME, Sarasa JL, Pestaña A and Rey JA: Allelic loss at $1 p$ and $19 q$ frequently occurs in association and may represent early oncogenic events in oligodendroglial tumors. Int J Cancer 64 207-210, 1995.

28. Cairncross JG, Ueki K, Zlatescu MC, Lisle DK, Finkelstein DM, Hammond RR, Silver JS, Stark PC, Macdonald DR, Ino Y, et al: Specific genetic predictors of chemotherapeutic response and survival in patients with anaplastic oligodendrogliomas. J Natl Cancer Inst 90: 1473-1479, 1998.

29. Baumann GS, Ino Y, Ueki K, Zlatescu MC, Fisher BJ, Macdonald DR, Stitt L, Louis DN and Cairncross JG: Allelic loss of chromosome $1 \mathrm{p}$ and radiotherapy plus chemotherapy in patients with oligodendrogliomas. Int J Radiat Oncol Biol Phys 48: 825-830, 2000.

30. Hagel C, Krog B, Laas R and Stavrou DK: Prognostic relevance of TP53 mutations, p53 protein, Ki-67 index and conventional histologic grading in oligodendrogliomas. J Exp Clin Cancer Res 18: 305-309, 1999.

31. Korshunov A and Golanov A: The prognostic significance of vascular endothelial growth factor (VEGF C-1) immunoexpression in oligodendroglioma. An analysis of 91 cases. J Neurooncol 48: 13-19, 2000.

32. Di Rocco F, Carroll RS, Zhang J and Black PM: Platelet-derived growth factor and its receptor expression in human oligodendrogliomas. Neurosurg 42: 341-346, 1998.

33. Iwabuchi H, Sakamoto M, Sakunaga H, Ma YY, Carcangiu ML, Pinkel D, Yang-Feng TL and Gray JW: Genetic analysis of benign, low-grade, and high-grade ovarian tumors. Cancer Res 55: 6172-6180, 1995.

34. Parker BC, Annala MJ, Cogdell DE, Granberg KJ, Sun Y, Ji P, Li X, Gumin J, Zheng H, Hu L, et al: The tumorigenic FGFR3-TACC3 gene fusion escapes miR-99a regulation in glioblastoma. J Clin Invest 123: 855-865, 2013.

35. Singh D, Chan JM, Zoppoli P, Niola F, Sullivan R, Castano A, Liu EM, Reichel J, Porrati P, Pellegatta S, et al: Transforming fusions of FGFR and TACC genes in human glioblastoma. Science 337: 1231-1235, 2012.

36. Jones DT, Kocialkowski S, Liu L, Pearson DM, Bäcklund LM, Ichimura $\mathrm{K}$ and Collins VP: Tendem duplication producing a novel oncogenic BRAF fusion gene defines the majority of pilocytic astrocytomas. Cancer Res 68: 8673-8677, 2008

37. Cao J, Gao T, Stanbridge EJ and Irie R: RBP1L1, a retinoblastomabinding protein-related gene encoding an antigenic epitope abundantly expressed in human carcinomas and normal testis. J Natl Cancer Inst 93: 1159-1165, 2001.

38. Neidhart M: Chapter 14-DNA Methylation in Growth Retardation, In DNA Methylation and Complex Human Disease. Academic Press, Oxford, pp241-259, 2016.

39. Goldberger N, Walker RC, Kim CH, Winter S and Hunter KW: Inherited variation in miR-290 expression suppresses breast cancer progression by targeting the metastasis susceptibility gene Arid4b. Cancer Res 73: 2671-2681, 2013.

40. Wu MY, Eldin KW and Beaudet AL: Identification of chromatin remodeling genes Arid4a and Arid4b as leukemia suppressor genes. J Natl Cancer Inst 100: 1247-1259, 2008.

41. Tsai WC, Hueng DY, Nieh S and Gao HW: ARID4B is a good biomarker to predict tumour behaviour and decide WHO grades in gliomas and meningiomas. J Clin Pathol 70: 162-167, 2017.

42. Pal J, Patil V, Mondal B, Shukla S, Hegde AS, Arivazhagan A, Santosh V and Somasundaram K: Epigenetically silenced GNG4 inhibits SDF1 $\alpha / C X C R 4$ signaling in mesenchymal glioblastoma. Genes Cancer 7: 136-147, 2016.

43. Mercier S, Küry S, Shaboodien G, Hounier DT, Khumalo NP, Bou-Hanna C, Bodak N, Cormier-Daire V, David A, Faivre L, et al: Mutations in FAM111B cause hereditary fibrosing poikiloderma with tendon contracture, myopathy, and pulmonary fibrosis. Am J Hum Genet 93: 1100-1107, 2013.

44. Goussot R, Prasad M, Stoetzel C, Lenormand C, Dollfus H and Lipsker D: Expanding phenotype of hereditary fibrosing poikiloderma with tendon contractures, myopathy, and pulmonary fibrosis caused by FAM111B mutations: Report of an additional family raising the question of cancer predisposition and a short review of early-onset poikiloderma. JAAD Case Rep 3: 143-150, 2017.

45. Unger S, Górna MW, Le Béchec A, Do Vale-Pereira S, Bedeschi MF, Geiberger S, Grigelioniene G, Horemuzova E, Lalatta F, Lausch E, et al: FAM111A mutations result in hypoparathyroidism and impaired skeletal development. Am J Hum Genet 92: 990-995, 2013.
46. Stirnimann CU, Petsalaki E, Russell RB and Müller CW: WD40 proteins propel cellular networks. Trends Biochem Sci 35: 565-574, 2010.

47. Fransson A, Ruusala A and Aspenström P: Atypical Rho GTPases have roles in mitochondrial homeostasis and apoptosis. J Biol Chem 278: 6495-6502, 2003.

48. Fransson S, Ruusala A and Aspenström P: The atypical Rho GTPases Miro-1 and Miro-2 have essential roles in mitochondrial trafficking. Biochem Biophys Res Commun 344: 500-510, 2006.

49. Caino MC, Seo JH, Aguinaldo A, Wai E, Bryant KG, Kossenkov AV, Hayden JE, Vaira V, Morotti A, Ferrero S, et al: A neuronal network of mitochondrial dynamics regulates metastasis. Nat Commun 7: 13730, 2016.

50. Garnis C, Coe BP, Zhang L, Rosin MP and Lam WL: Overexpression of LRP12, a gene contained within an 8 q22 amplicon identified by high-resolution array $\mathrm{CGH}$ analysis of oral squamous cell carcinomas. Oncogene 23: 2582-2586, 2004.

51. Bethge N, Honne H, Andresen K, Hilden V, Trøen G, Liestøl K, Holte H, Delabie J, Lind GE and Smeland EB: A gene panel, including LRP12, is frequently hypermethylated in major types of B-cell lymphoma. PLoS One 9: e104249, 2014.

52. Robens BK, Gembé E, Fassunke J, Becker AJ, Schoch S and Grote A: Abundance of LRP12 C-rs9694676 allelic promoter variant in epilepsy-associated gangliogliomas. Life Sci 155: 70-75, 2016.

53. Gong Y, Schumacher SE, Wu WH, Tang F, Beroukhim R and Chan TA: Pan-cancer analysis links PARK2 toBCL-XL-dependent control of apoptosis. Neoplasia 19: 75-83, 2017.

54. Andersen LB, Ballester R, Marchuk DA, Chang E, Gutmann DH, Saulino AM, Camonis J, Wigle M and Collins FS: A conserved alternative splice in the von Recklinghausen neurofibromatosis (NF1) gene produces two neurofibromin isoforms, both of which have GTPase-activating protein activity. Mol Cell Biol 13: 487-495, 1993

55. BanerjeeS,Crouse NR,EmnettRJ, Gianino SM and Gutmann DH: Neurofibromatosis-1 regulates mTOR-mediated astrocyte growth and glioma formation in a TSC/Rheb-independent manner. Proc Natl Acad Sci USA 108: 15996-16001, 2011.

56. Szudek J, Birch P, Riccardi VM, Evans DG and Friedman JM: Associations of clinical features in neurofibromatosis 1 (NF1). Genet Epidemiol 19: 429-439, 2000.

57. Gutmann DH, Rasmussen SA, Wolkenstein P, MacCollin MM, Guha A, Inskip PD, North KN, Poyhonen M, Birch PH and Friedman JM: Gliomas presenting after age 10 in individuals with neurofibromatosis type 1 (NF1). Neurology 59: 759-761, 2002.

58. Nielsen GP, Stemmer-Rachamimov AO, Ino Y, Moller MB, Rosenberg AE and Louis DN: Malignant transformation of neurofibromas in neurofibromatosis 1 is associated with CDKN2A/p16 inactivation. Am J Pathol 155: 1879-1884, 1999.

59. Legius E, Dierick H, Wu R, Hall BK, Marynen P, Cassiman JJ and Glover TW: TP53 mutations are frequent in malignant NF1 tumors. Genes Chromosomes Cancer 10: 250-255, 1994.

60. Vizcaíno MA, Shah S, Eberhart CG and Rodriguez FJ: Clinico-pathologic implications of NF1 gene alterations in diffuse gliomas. Human Pathology 46: 1323-1330, 2015.

61. Bruzek AK, Zureick AH, McKeever PE, Garton HJL, Robertson PL, Mody R and Koschmann CJ: Molecular characterization reveals NF1 deletions and FGFR1-activating mutations in a pediatric spinal oligodendroglioma. Pediatr Blood Cancer 64: e26346, 2017.

62. Giachino C, Lantelme E, Lanzetti L, Saccone S, Bella Valle G and Migone N: A Novel SH3-containing human gene family preferentially expressed in the central nervous system. Genomics 41: 427-434, 1997.

63. Sittler A, Walter S, Wedemeyer N, Hasenbank R, Scherzinger E, Eickhoff H, Bates GP, Lehrach H and Wanker EE: SH3GL3 associates with the huntingtin exon 1 protein and promotes the formation of polygln-containing protein aggregates. Mol Cell 2: 427-436, 1998

64. Huebner K, Kastury K, Druck T, Salcini AE, Lanfrancone L, Pelicci G, Lowenstein E, Li W, Park SH, Cannizzaro L, et al: Chromosome locations of genes encoding human signal transduction adapter proteins, Nck (NCK), Shc (SHC1), and Grb2 (GRB2). Genomics 22: 281-287, 1994.

65. Fang WJ, Zheng Y, Wu LM, Ke QH, Shen H, Yuan Y and Zheng SS: Genome-wide analysis of aberrant DNA methylation for identification of potential biomarkers in colorectal cancer patients. Asian Pac J Cancer Prev 13: 1917-1921, 2012. 
66. Chen R, Zhao H, Wu D, Zhao C, Zhao W and Zhou X: The role of SH3GL3 in myeloma cell migration/invasion, stemness and chemo-resistance. Oncotarget 7: 73101-73113, 2016.

67. Delic S, Lottmann N, Jetschke K, Reifenberger G and Riemenschneider MJ: Identification and functional validation of CDH11, PCSK6 and SH3GL3 as novel glioma invasion-associated candidate genes. Neuropathol Appl Neurobiol 38: 201-212, 2012.

68. Aphrothiti JH, Gopa I and David B: Solit: 2-Intracellula Signaling, In Abeloff's Clinical Oncology (Fifth edition), John EN, James OA, James HD, Michael BK and Joel ET, (eds) Tepper, Content Repository Only, Philadelphia,pp22-39, 2014.
69. Zhu Y, Zhang X, Wang L, Ji Z, Xie M, Zhou X, Liu Z, Shi H and Yu R: Loss of SH3GL2 promotes the migration and invasion behaviours of glioblastoma cells through activating the STAT3/MMP2 signalling. J Cell Mol Med 21: 2685-2694, 2017.

70. Wiederhold T, Lee MF, James M, Neujahr R, Smith N, Murthy A, Hartwig J, Gusella JF and Ramesh V: Magicin, a novel cytoskeletal protein associates with the NF2 tumor suppressor merlin and Grb2. Oncogene 23: 8815-8825, 2004.

(i) () $\odot$ This work is licensed under a Creative Commons EY NG ND Attribution-NonCommercial-NoDerivatives 4.0 International (CC BY-NC-ND 4.0) License. 